\title{
Design and Testing of Analog Antilock Braking System (AABS)
}

\author{
Dr.B.Biju ${ }^{\# 1}$, Abhishek P A ${ }^{2}$, Arshaque $\mathrm{M}^{3}$, Don $\mathrm{C} \mathrm{P}^{4}$, Salmanul FarizT T \\ ${ }^{1}$ Professor, Department of mechanical engineering, \\ Mar Athanasius College of Engineering, Kerala, India 686666 \\ \# bbiju2008@gmail.com \\ 2,3,4,5 UG Scholar, Department of mechanical engineering, \\ Mar Athanasius College of Engineering, Kerala, India 686666
}

\begin{abstract}
Most of the commercial vehicles nowadays use Antilock Braking System (ABS). The ABS is controlled electronically and hence it is very costly. Replacing the electronic control by mechanical control system, we are introducing an efficient Analog Antilock Braking System (AABS) by making certain modifications in already existing hydraulic braking system. The design and testing of AABS based on mechanical system control is addressed in this manuscript.
\end{abstract}

Keywords- Spring valve system, Analog antilock braking system, spring constant, mechanical system control, preload.

\section{INTRODUCTION}

Most of the commercial vehicles nowadays use Antilock Braking System (ABS). An antilock braking system or anti skid braking system (ABS) is an automobile safety system that allows the wheels on a motor vehicle to maintain tractive contact with the road surface according to driver inputs while braking, preventing the wheels from locking up and avoiding uncontrolled skidding. ABS provide stable braking characteristics on all road surfaces, hence avoids overturning of the vehicle. ABS control is highly nonlinear control problem due to the complicated relationship between its components and parameters. ABS modulates the brake line pressure independent of the pedal force. The stopping distance after using ABS system considerably reduced. ABS is controlled electronically and is very costly.

We are addressing the design and testing of an efficient Analog Antilock Braking System (AABS) by making certain modifications in already existing hydraulic braking system. It completely works on mechanical systems control. It is obvious that efficient design of braking systems is to reduce accidents. It is designed to keep a vehicle steerable and stable during heavy braking moments by preventing wheel lock. To make the vehicle stop in a shortest distance possible while maintaining the directional control.

Ayman A. Aly, El-Shafei Zeidan, Ahmed Hamed, Farhan Salem, “ An Antilock-Braking Systems (ABS) Control describes that, antilock braking system or anti skid braking system (ABS) preventing the wheels from locking up and avoiding uncontrolled skidding .ABS provide stable braking characteristics on all road surfaces, hence avoids overturning of the vehicle. Analog antilock braking systems also provide stable braking characteristics on all road surfaces.

\section{WORKING}

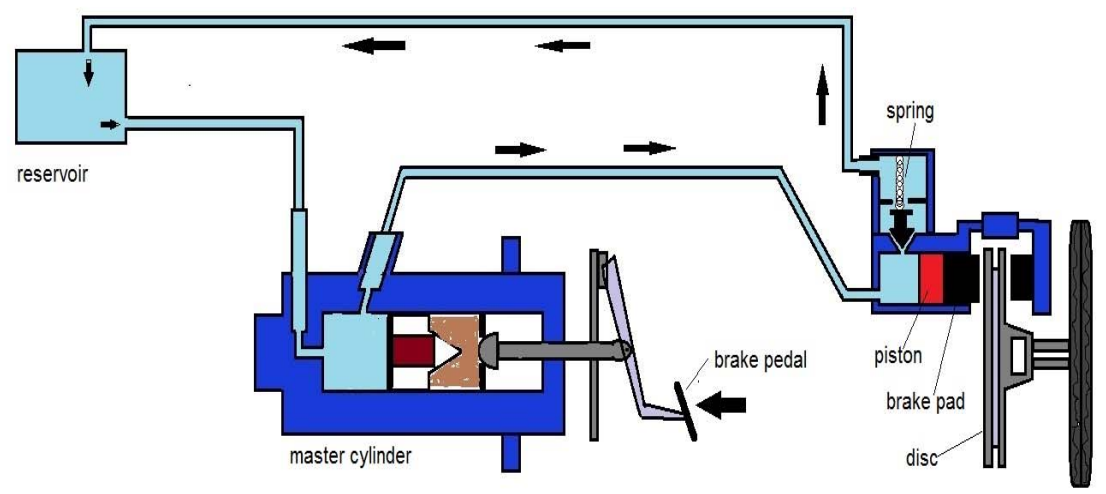

Fig.1: schematic diagram of Analog Antilock Braking System (AABS) 
In normal braking system, when the pedal is applied the brake fluid flows to the calliper cylinder from the master cylinder through hoses and the brake pad pushed onto the rotating disc and stops the vehicle. When pressure on the calliper cylinder increases beyond a particular pressure the wheels of the vehicle will be locked, it leads the vehicle to skid and is very dangerous. To avoid this condition, we use analogue antilock braking system. In the above figure we can see a spring valve system attached to the calliper cylinder. When the pressure on the calliper cylinder increases beyond critical pressure the spring valve opens and the excess fluid moves upwards. This excess brake fluid is stored in a reservoir. The reservoir delivers the fluid to the master cylinder.

\section{COMPONENTS}

The main components of the spring valve are
a) Spring valve
b) Caliper cylinder
c) Master cylinder
d) Disc
e) Reservoir

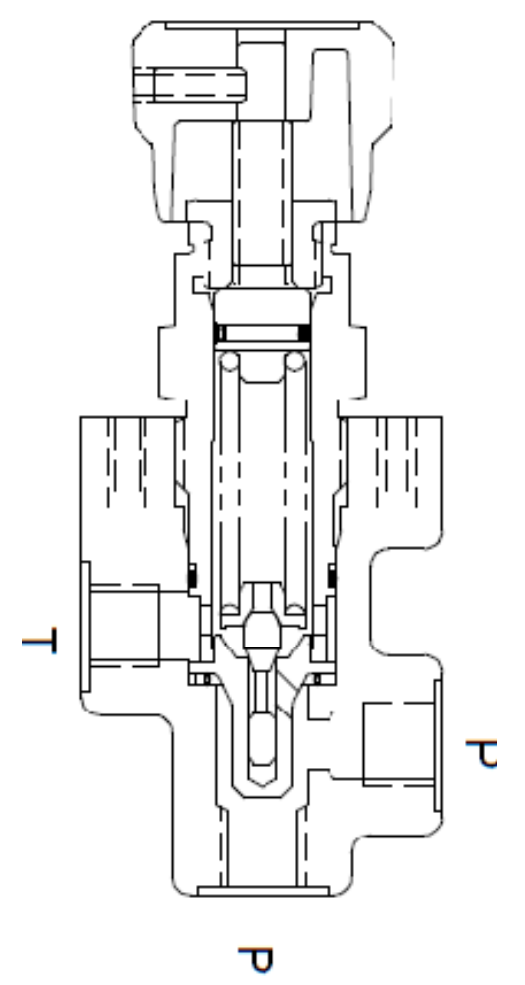

Fig 2: 2D representation of spring valve (Courtesy: Polyhydron Group Company)

\section{IMPORTANTCE OF AABS}

i. Analog antilock braking system is very economical compared to normal abs system. Since there is no need for electronic circuits and devices the cost reduces and become economical also there by reduces E-waste.

ii. $\quad$ AABS reduce the stopping distance. In this the locking of the tyres do not takes place.

iii. This works only at critical conditions. When critical pressure reaches, the additional spring valve system opens and the fluid flows through the valves and thereby reduces the pressure in the piston. So skidding of the tyres can be avoided.

iv. The rolling of the tyres takes place according to the static friction. At critical condition, the pressure applied on the piston is limited to critical pressure. Thus we can maintain it in the static friction condition and reduce the wearing of the tyres.

v. This braking system provides stable braking on wet and dry surfaces. At wet conditions, we have to reduce the critical pressure. So at wet condition the pre load of the spring is less than that of dry condition. 


\section{PRELOAD AND SPRING CONSTANT CALCULATION}

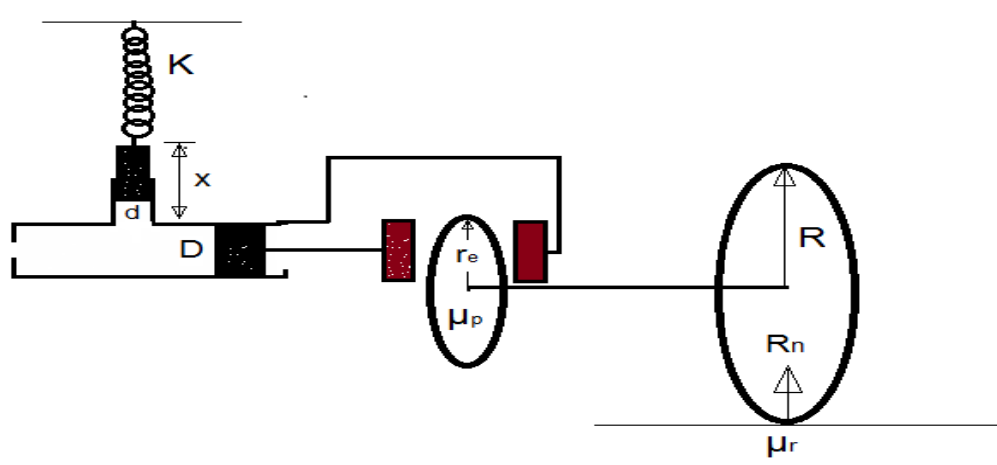

Fig3: Dimensions of components

$\mathrm{R}$ - radius of tyre

$r_{e}$ - effective radius of disc (distance from center of the disc to center of brake pad )

D - diameter of caliper piston

d - diameter of valve pin

$\mu_{\mathrm{r}}$ - coefficient of friction between road and tyre

$\mu_{\mathrm{p}}$ - coefficient of friction between brake disc and brake pad

$\mathrm{K}$ - spring constant

$\mathrm{X}$ - preload compression

$\mathrm{Rn}$ - normal reaction on tyre

$\mathrm{N}$ - Number of caliper cylinders

i. Maximum force exerted by the friction on the tyre

$$
\operatorname{Fmax}=\mu_{\mathrm{r}} \mathrm{Rn}
$$

ii. Maximum torque possessed by this force

$$
\tau \max =\mathrm{R} \text { Fmax }=\mu_{\mathrm{r}} \mathrm{Rn} \mathrm{R}
$$

iii. Normal force exerted by the caliper on the disc plate is ' $F c$ '.

iv. Frictional force generated at the disc plate

$$
\mathrm{Fd}=\mu_{\mathrm{p}} \mathrm{Fc}
$$

v. Torque possessed by this force on the disc plate

$$
\tau_{\mathrm{d}}=\mu_{\mathrm{p}} \mathrm{Fc} \mathrm{r}_{\mathrm{e}}
$$

vi. Force just required to stop the rotation of the tyre

$$
\begin{aligned}
& \tau_{\mathrm{d}}=\tau \max \\
& \operatorname{Fmax}=\left(\mu_{\mathrm{r}} / \mu_{\mathrm{p}}\right) *\left(\mathrm{R} / \mathrm{r}_{\mathrm{e}}\right) * \mathrm{Rn}
\end{aligned}
$$

vii. Critical pressure corresponding to maximum caliper force

$$
\begin{array}{r}
\operatorname{Pmax}=\text { Fmax } / \mathrm{A} \\
=\left(4 / \pi \mathrm{D}^{2}\right) *\left(\mu_{\mathrm{r}} / \mu_{\mathrm{p}}\right) *\left(\mathrm{R} / \mathrm{r}_{\mathrm{e}}\right) * \mathrm{Rn}
\end{array}
$$

Pressure exerted by the spring on the fluid

$$
\mathrm{P}=\mathrm{Fs} / \mathrm{A}=\left(4 / \pi \mathrm{D}^{2}\right)^{*} \mathrm{Fs}
$$

viii. Pressure exerted by the spring on the fluid must be equal to

Critical pressure, $\quad \mathrm{P}=\mathrm{Pmax}$

$$
\text { Spring force, } \quad \mathrm{Fs}=(\mathrm{d} / \mathrm{D})^{2} *\left(\mu_{\mathrm{r}} / \mu_{\mathrm{p}}\right) *\left(\mathrm{R} / \mathrm{r}_{\mathrm{e}}\right) * \mathrm{Rn}
$$




\section{FREE BODY DIAGRAM OF VEHICLE IN DYNAMIC CONDITION}

$\mathrm{N}$ - Number of caliper cylinders

$\mathrm{m}$ - Mass of the vehicle

ad - Deceleration due to frictional force at braking condition

$\mathrm{W}$ - Weight of the vehicle

$\mathrm{h}-$ Vertical height of the center of gravity of vehicle

$\mathrm{Z}$ - Length between front tyre and center of gravity in horizontal direction

$\mathrm{L}$ - Length between center of front and rear tyre

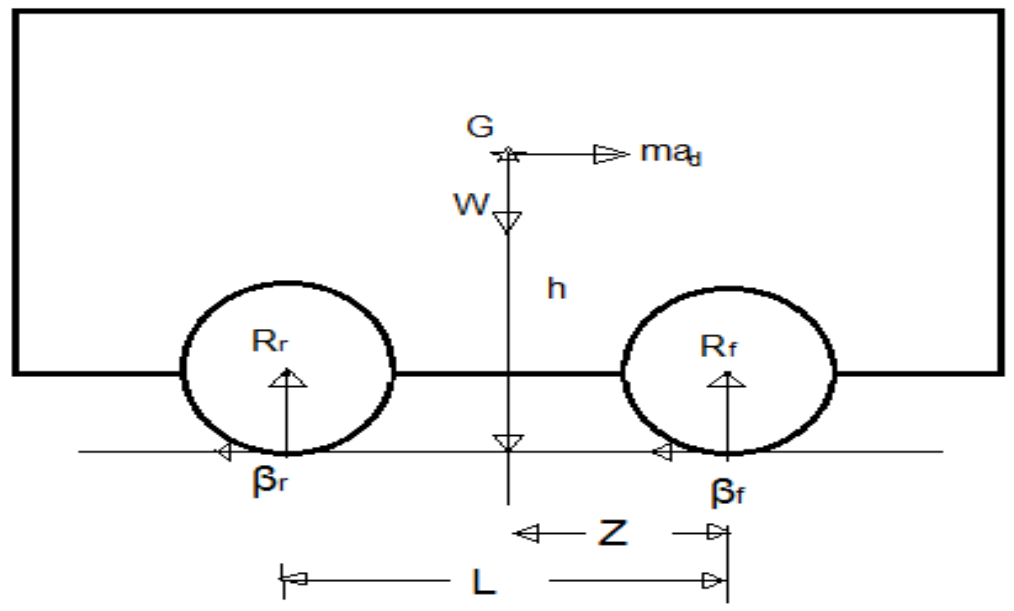

Fig4: Force on tyre and vehicle body

Applying static equilibrium condition in vertical direction

$$
\mathrm{Rf}+\mathrm{Rr}=\mathrm{W}
$$

Applying dynamic condition

$$
\operatorname{mad}=\beta \mathrm{f}+\beta \mathrm{r}
$$

$\beta r=\mu R r \quad$ [ frictional force at rear tyre ]

$\beta \mathrm{f}=\mu \mathrm{Rf} \quad[$ frictional force at front tyre ]

$$
\text { ie, } \quad \mu \mathrm{Rf}+\mu \mathrm{Rr}=\operatorname{mad} \Rightarrow \mu(\mathrm{Rf}+\mathrm{Rr})=\operatorname{mad} \Rightarrow \mu \mathrm{W}=\operatorname{mad}
$$

Applying momentum equilibrium at rear wheel,

$$
\begin{aligned}
\mathrm{Rf} L=W(\mathrm{~L}-\mathrm{Z})+ & \operatorname{mad} \mathrm{h} \\
& \mathrm{Rf}=(\mathrm{W} / \mathrm{L}) *\left(\mathrm{~L}-\mathrm{Z}+\mu_{\mathrm{r}} \mathrm{h}\right)
\end{aligned}
$$

Applying momentum equilibrium at front wheel,

$$
\begin{aligned}
& \mathrm{Rr} L+\operatorname{mad} \mathrm{h}=\mathrm{WZ} \\
& \mathrm{Rr}=(\mathrm{W} / \mathrm{L})^{*}\left(\mathrm{Z}-\mu_{\mathrm{r}} \mathrm{h}\right)
\end{aligned}
$$

Value of Rf \& Rr substitute in equation for spring force

$$
\begin{gathered}
\mathrm{Fs}=(\mathrm{d} / \mathrm{D})^{2} *\left(\mu_{\mathrm{r}} / \mu_{\mathrm{p}}\right) *\left(\mathrm{R} / \mathrm{r}_{\mathrm{e}}\right) * \mathrm{Rn} \\
\mathrm{Rn}=\mathrm{Rf} \text { for front tyre } \\
\mathrm{Rn}=\mathrm{Rf} \text { for rear tyre } \\
\mathrm{Fsf}=(1 / \mathrm{N}) *(\mathrm{~d} / \mathrm{D})^{2} *\left(\mu_{\mathrm{r}} / \mu_{\mathrm{p}}\right) *\left(\mathrm{R} / \mathrm{r}_{\mathrm{e}}\right)^{*}(\mathrm{~W} / \mathrm{L})^{*}\left(\mathrm{~L}-\mathrm{Z}+\mu_{\mathrm{r}} \mathrm{h}\right) \\
\mathrm{Fsr}=(1 / \mathrm{N}) *(\mathrm{~d} / \mathrm{D})^{2 *}\left(\mu_{\mathrm{r}} / \mu_{\mathrm{p}}\right) *\left(\mathrm{R} / \mathrm{r}_{\mathrm{e}}\right) *(\mathrm{~W} / \mathrm{L}) *\left(\mathrm{Z}-\mu_{\mathrm{r}} \mathrm{h}\right)
\end{gathered}
$$

Fsf \& Fsr are the preload force of spring at front \& rear tyre respectively.

For spring, $\quad \mathrm{Fs}=\mathrm{Kx}$

Critical pressure in front caliper cylinder,

$$
\begin{gathered}
\text { Ie, } \operatorname{KfXf}=(1 / \mathrm{N})^{*}(\mathrm{~d} / \mathrm{D})^{2} *\left(\mu_{\mathrm{r}} / \mu_{\mathrm{p}}\right) *\left(\mathrm{R} / \mathrm{r}_{\mathrm{e}}\right) *(\mathrm{~W} / \mathrm{L})^{*}\left(\mathrm{~L}-\mathrm{Z}+\mu_{\mathrm{r}} \mathrm{h}\right) \\
\mathrm{Kr} \mathrm{Xr}=(1 / \mathrm{N})^{*}(\mathrm{~d} / \mathrm{D})^{2} *\left(\mu_{\mathrm{r}} / \mu_{\mathrm{p}}\right) *\left(\mathrm{R} / \mathrm{r}_{\mathrm{e}}\right) *(\mathrm{~W} / \mathrm{L}) *\left(\mathrm{Z}-\mu_{\mathrm{r}} \mathrm{h}\right)
\end{gathered}
$$

$$
\mathrm{KfXf} / \mathrm{d}^{2}=(1 / \mathrm{N}) *(1 / \mathrm{D})^{2} *\left(\mu_{\mathrm{r}} / \mu_{\mathrm{p}}\right) *(\mathrm{R} / \mathrm{re}) *(\mathrm{~W} / \mathrm{L}) *\left(\mathrm{~L}-\mathrm{Z}+\mu_{\mathrm{r}} \mathrm{h}\right)
$$


From this equation it is cleared that the value of preload depends on many parameters so for the easiness we have to fix any of the parameter either $\mathrm{K}$ or $\mathrm{X}$. Changing of $\mathrm{K}$ is not practically possible that easy as changing of $\mathrm{X}$. So at the point of design part we giving an initial compression $\mathrm{X} 0$ and calculate the value of $\mathrm{K}$. Let $\mathrm{Xf}=\mathrm{Xr}$ $=\mathrm{X} 0$

Therefore,

$$
\begin{gathered}
\mathrm{Kf}=(1 / \mathrm{X} 0)^{*}(\mathrm{~d} / \mathrm{D})^{2} *\left(\mu_{\mathrm{r}} / \mu_{\mathrm{p}}\right) *\left(\mathrm{R} / \mathrm{r}_{\mathrm{e}}\right) *(\mathrm{~W} / \mathrm{L}) *\left(\mathrm{~L}-\mathrm{Z}+\mu_{\mathrm{r}} \mathrm{h}\right) \\
\mathrm{Kr}=(1 / \mathrm{X} 0)^{*}(\mathrm{~d} / \mathrm{D})^{2 *}\left(\mu_{\mathrm{r}} / \mu_{\mathrm{p}}\right) *\left(\mathrm{R} / \mathrm{r}_{\mathrm{e}}\right) *(\mathrm{~W} / \mathrm{L}) *\left(\mathrm{Z}-\mu_{\mathrm{r}} \mathrm{h}\right) \\
\text { VII. CALIBRATION OF PRELOAD }
\end{gathered}
$$

There may be some difference in preload in actual condition. Spring constant of spring for front and rear tyre are $\mathrm{Kf}$ and $\mathrm{Kr}$ respectively.

Step 1:

Preload the valve as per the assumed preload compression $\mathrm{X} 0$.

So force provided by the spring $\mathrm{Kf} \mathrm{X} 0, \mathrm{Kr} \mathrm{X} 0$ for the front and rear wheel respectively.

Step 2:

Now drive the vehicle at $80 \mathrm{~km} / \mathrm{hr}$ and applying maximum brake and check whether the tyre is locked or not.

Step 3:

Case 1- tyre is locked; reduce the preload of X from X0.

Case 2- tyre is not locked; increase the preload of X from X0.

Step 4:

Repeat the experiment and find the value of $\mathrm{X}$ just before the tyre has locked up.

So that actual value of $\mathrm{X}=\mathrm{X} 0 \pm \Delta \mathrm{X}$

Now we get both the value of spring constant and initial compression required for dry and wet condition and also front and rear tyre.

Now adjust the initial compression of spring from $\mathrm{X} 0$ to $\mathrm{X}$. Hence calibration is done. We will able to maintain maximum possible pressure at caliper cylinder without locking up of the tyre.

Using calibrated equation from 17, 18, 19

For front brake,

$$
\mathrm{X}=(1 / \mathrm{Kf})^{*}(\mathrm{~d} / \mathrm{D})^{2 *}\left(\mu_{\mathrm{r}} / \mu_{\mathrm{p}}\right) *\left(\mathrm{R} / \mathrm{r}_{\mathrm{e}}\right)^{*}(\mathrm{~W} / \mathrm{L})^{*}\left(\mathrm{~L}-\mathrm{Z}+\mu_{\mathrm{r}} \mathrm{h}\right) \pm \Delta \mathrm{X}
$$

For rear brake,

$$
\mathrm{X}=(1 / \mathrm{Kr})^{*}(\mathrm{~d} / \mathrm{D})^{2} *\left(\mu_{\mathrm{r}} / \mu_{\mathrm{p}}\right) *\left(\mathrm{R} / \mathrm{r}_{\mathrm{e}}\right) *(\mathrm{~W} / \mathrm{L}) *\left(\mathrm{Z}-\mu_{\mathrm{r}} \mathrm{h}\right) \pm \Delta \mathrm{X}
$$

From the equation it's clear that preload compression varying with different parameters,

$$
\begin{array}{ll}
\mathrm{X} \alpha \mu_{\mathrm{r}} & \mathrm{X} \alpha 1 / \mu_{\mathrm{p}} \\
\mathrm{X} \alpha \mathrm{d}^{2} & \mathrm{X} \alpha 1 / \mathrm{D}^{2} \\
\mathrm{X} \alpha 1 / \mathrm{r}_{\mathrm{e}} &
\end{array}
$$

\section{INFERENCE}

- If friction between road and tyre reduces then we need low value of X. So at wet condition the value of $\mathrm{X}$ will be less than that of at dry condition.

- Effective radius of disc brake is inversely proportional to the preload compression. Higher the radius lower the preload required.

- Higher the value of coefficient of friction between brake pad, lower the preload required.

- The value of the diameter of both cylinder and hole come very important and high influence. So we have to reduce the value of $d$ and increase the value of $D$ for a low preload.

IX. SPRING CONSTANT \& CRITICAL PRESSURE CALCULATION FOR THE TEST VEHICLE “PULSAR 150”

$\mathrm{KfXf}=(1 / \mathrm{N}) *(\mathrm{~d} / \mathrm{D})^{2} *\left(\mu_{\mathrm{r}} / \mu_{\mathrm{p}}\right) *\left(\mathrm{R} / \mathrm{r}_{\mathrm{e}}\right)^{*}(\mathrm{~W} / \mathrm{L}) *\left(\mathrm{~L}-\mathrm{Z}+\mu_{\mathrm{r}} \mathrm{h}\right)$

For pulsar 150 , we take

$$
\begin{aligned}
& \mu_{\mathrm{r}}=0.7 \\
& \mu_{\mathrm{p}}=0.4 \\
& \mathrm{D}=0.028 \mathrm{~m}
\end{aligned}
$$

Grows weight, $\mathrm{W}=2452.5 \mathrm{~N}$

Length of the vehicle, $\mathrm{L}=1.8353 \mathrm{~m}$ 
Height of the vehicle $=1.4378 \mathrm{~m}$

Effective radius of disc, $r_{\mathrm{e}}=0.120 \mathrm{~m}$

Radius of tyre, $\quad \mathrm{R}=0.3086 \mathrm{~m}$

Position of center of gravity, $\mathrm{Z}=0.685 \mathrm{~m}$

Number of caliper cylinder, $\mathrm{N}=2$

Therefore equation 18 becomes,

$$
\begin{aligned}
\mathrm{Kf} \mathrm{Xf} / \mathrm{d}^{2}= & (1 / 2) *\left(1 / .028^{2}\right) *(0.7 / 0.4) *(0.3086 / 0.120) \\
& *(2452 / 1.8353) *(2.055-0.685+0.7 * 1.4378) \\
= & 7318132.895 \mathrm{~N} / \mathrm{m}^{2} \\
= & 73.18 \mathrm{bar}
\end{aligned}
$$

Critical pressure $=73.18$ bar

Spring constant, $\mathrm{Kf}=\left(7318132.895 * \mathrm{~d}^{2}\right) / \mathrm{Xf}$

$$
\begin{aligned}
& =\left(7318132.895 * 0.003^{2}\right) / 0.006 \\
& =10977.199 \mathrm{~N} / \mathrm{m}
\end{aligned}
$$

where, $\mathrm{d}=$ diameter of valve pin $=0.003 \mathrm{~m}$

$$
\mathrm{Xf}=\text { preload compression }=0.006 \mathrm{~m}
$$

\section{$\mathrm{X}$. TESTING AND OBSERVATIONS}

We have conducted test on AABS at different braking conditions (braking force). The data obtained from the experiment is given below.

\begin{tabular}{|c|c|c|c|c|}
\hline \multicolumn{2}{|c|}{} & \multicolumn{3}{|c|}{ PRESSURE (bar) } \\
\hline SI No & $\begin{array}{c}\text { Time } \\
(\mathbf{s e c})\end{array}$ & $\begin{array}{c}\text { Normal Condition } \\
(\mathbf{F = 1 5 0 N )}\end{array}$ & $\begin{array}{c}\text { With AABS } \\
\text { Condition (F=350N) }\end{array}$ & $\begin{array}{c}\text { Without AABS } \\
\text { Condition (F=500N) }\end{array}$ \\
\hline 1 & 0 & 0 & 0 & 0 \\
\hline 2 & 0.5 & 10 & 20 & 23 \\
\hline 3 & 1 & 18 & 38 & 43 \\
\hline 4 & 1.5 & 24 & 54 & 61 \\
\hline 5 & 2 & 32 & 71 & 75 \\
\hline 6 & 2.5 & 37 & 79 & 81 \\
\hline 7 & 3 & 41 & 67 & 82 \\
\hline 8 & 3.5 & 43 & 69 & 84 \\
\hline 9 & 4 & 45 & 77 & 85 \\
\hline 10 & 4.5 & 47 & 70 & 86 \\
\hline 11 & 5 & 49 & 73 & 87 \\
\hline
\end{tabular}

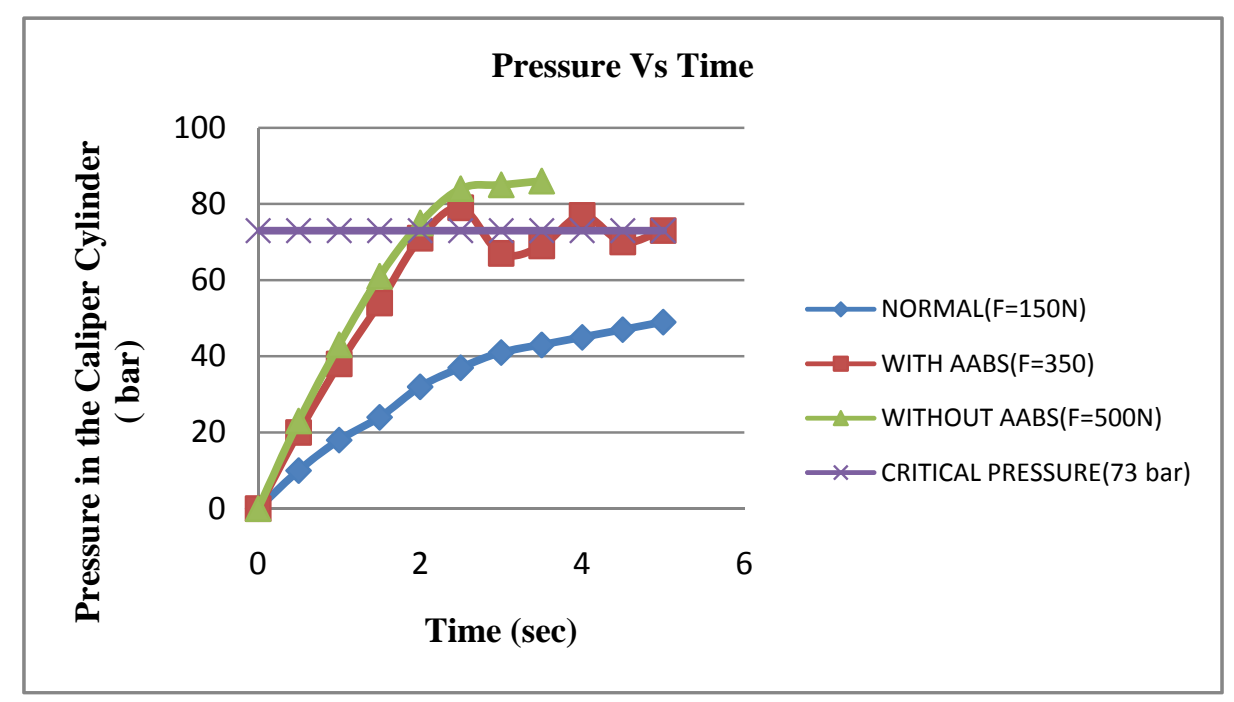




\section{ADVANTAGES OF AABS}

i. It is very economical compared to electronic assisted systems.

ii. It works efficient at critical road conditions.

iii. No need of sensors and other complicated electronic systems.

iv. Reduce the stopping distance considerably.

v. Skidding of tyres can be reduced significantly.

vi. Locking of tyre can be avoided.

vii. Reduce the wearing of tyres and increase tyre life.

\section{LIMITATIONS OF AABS}

i. Inconsistent stoppage time of the vehicle.

ii. If the road surfaces consist of different coefficient of friction, this system will be difficult in four wheeler vehicle.

\section{CONCLUSIONS}

Recent technology developments cater advances in the automobiles braking system. In vehicles without antilock brake systems, drivers who encounter slippery conditions may lose the stability of the vehicle because of locked up wheels. Analog Antilock Braking System (AABS) helps drivers to have better control of the vehicle in certain road conditions where hard braking may be necessary. The present model of Analog Antilock Braking System is developed by making certain modifications in already existing hydraulic braking system. A spring valve system is used to control the pressure on caliper cylinder below the critical pressure. We can use this system also as a normal braking system. It does not need the electronic circuits and sensors and hence is very economical. Its successful implementation will allow avoiding road crashes with maximum efficiency and uncompromised vehicle stability during emergency braking.

\section{REFERENCES}

[1] J. Song, H. Kim and K. Boo, “A study on an Anti-Lock Braking System Controller and Rear-Wheel Controller to Enhance Vehicle Lateral Stability," Proceedings of the Institution of Mechanical Engineers, Part D: Journal of Automobile Engineering, Vol. 221 No. 7, 2007, pp. 777- 787.

[2] Ayman A. Aly, El-Shafei Zeidan, Ahmed Hamed, Farhan Salem, “ An Antilock-BrakingSystems (ABS) Control, Intelligent Control and Automation, 2011, vol.2, 186-195.

[3] A B Sharkawy, "Genetic Fuzzy Self-tuning PID Controllers for Antilock Braking Systems" Engineering Applications of Artificial Intelligence, 2010, Vol.23, pp. 1041-1052.

[4] P. E. Wellstead and N. B. O. L. Pettit, "Analysis and Redesign of an Antilock Brake System Controller", IEEE Proceedings Control Theory Applications, Vol. 144, No. 5, September 2007,pp. 413-426.

[5] T. Tabo, N. Ohka, H. Kuraoka and M. Ohba, "Automotive Antiskid System Using ModernControl Theory," IEEE Proceedings, San Francisco, 2005, pp. 390-395.

[6] A. B. Will and S. H. Zak, “Antilock Brake System Mod-elling and Fuzzy Control,” International Journal of Vehi-cle Design, Vol. 24, No. 1, 2000, pp. 1-18.

[7] A. A. Aly, "Intelligent Fuzzy Control for Antilock Brake System with Road-Surfaces Identifier," 2010 IEEE In-ternational Conference on Mechatronics and Automation, Xi'an, 2010, pp. 2292-2299.

[8] Y. Oniz, E. Kayacan, O. Kaynak, A dynamic method to forecast the wheel slip for antilock braking system and its experimental evaluation, IEEE Transactions on Systems, Man, and Cybernetics Part B Cybernetics 39 (2) (2009) 551-560.

[9] B. Ozdalyan, Development of a slip control anti-lock braking system model, International Journal of Automotive Technology 9 (1) (2008) 71-80.

[10] Dattatraya K Chavan, Anish S Gorantiwar, Kunal R Nalamwar and Rites h G Deokar, A Comparative Study and Analysis of the Performance of Various Regenerative Braking Systems, .International Journal of Mechanical Engineering and Technology, 8(3), 2017 , pp. $66-76$ 